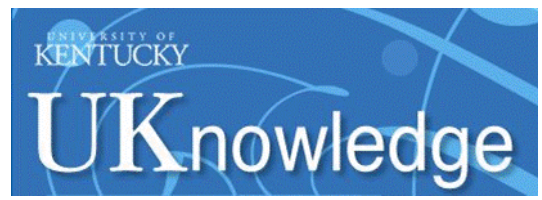

University of Kentucky

UKnowledge

\title{
Association of Altered Collagen Content and Lysyl Oxidase Expression in Degenerative Mitral Valve Disease
}

\author{
K-Raman Purushothaman \\ Icahn School of Medicine at Mount Sinai \\ Meerarani Purushothaman \\ Icahn School of Medicine at Mount Sinai \\ Irene C. Turnbull \\ Icahn School of Medicine at Mount Sinai \\ David H. Adams \\ Icahn School of Medicine at Mount Sinai \\ Anelechi Anyanwu \\ Icahn School of Medicine at Mount Sinai
}

See next page for additional authors

Follow this and additional works at: https://uknowledge.uky.edu/pathology_facpub

Part of the Cardiovascular System Commons, and the Pathology Commons

Right click to open a feedback form in a new tab to let us know how this document benefits you.

\section{Repository Citation}

Purushothaman, K-Raman; Purushothaman, Meerarani; Turnbull, Irene C.; Adams, David H.; Anyanwu, Anelechi; Krishnan, Prakash; Kini, Annapoorna; Sharma, Samin K.; O'Connor, William N.; and Moreno, Pedro R., "Association of Altered Collagen Content and Lysyl Oxidase Expression in Degenerative Mitral Valve Disease" (2017). Pathology and Laboratory Medicine Faculty Publications. 33.

https://uknowledge.uky.edu/pathology_facpub/33

This Article is brought to you for free and open access by the Pathology and Laboratory Medicine at UKnowledge. It has been accepted for inclusion in Pathology and Laboratory Medicine Faculty Publications by an authorized administrator of UKnowledge. For more information, please contact UKnowledge@lsv.uky.edu. 


\section{Association of Altered Collagen Content and Lysyl Oxidase Expression in Degenerative Mitral Valve Disease}

Digital Object Identifier (DOI)

https://doi.org/10.1016/j.carpath.2017.04.001

Notes/Citation Information

Published in Cardiovascular Pathology, v. 29, p. 11-18.

(C) 2017 Elsevier Inc. All rights reserved.

This manuscript version is made available under the CC-BY-NC-ND 4.0 license

https://creativecommons.org/licenses/by-nc-nd/4.0/.

The document available for download is the author's post-peer-review final draft of the article.

Authors

K-Raman Purushothaman, Meerarani Purushothaman, Irene C. Turnbull, David H. Adams, Anelechi Anyanwu, Prakash Krishnan, Annapoorna Kini, Samin K. Sharma, William N. O'Connor, and Pedro R. Moreno 


\title{
Association of Altered Collagen Content and Lysyl Oxidase Expression in Degenerative Mitral Valve Disease
}

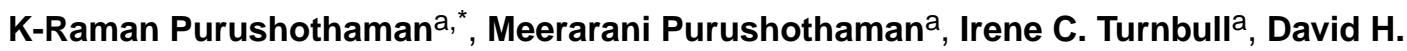 \\ Adams $^{b}$, Anelechi Anyanwu ${ }^{\mathrm{b}}$, Prakash Krishnan ${ }^{\mathrm{a}}$, Annapoorna Kini ${ }^{\mathrm{a}}$, Samin K. Sharma ${ }^{\mathrm{a}}$, \\ William N O'Connor', and Pedro R. Moreno ${ }^{\mathrm{a}}$ \\ aThe Zena and Michael A. Weiner Cardiovascular Institute and the Marie-Josée and Henry R. \\ Kravis Cardiovascular Health Center, Department of Medicine, Icahn School of Medicine at Mount \\ Sinai, New York, NY \\ bDepartment of Cardiovascular Surgery, Icahn School of Medicine at Mount Sinai, New York, NY \\ 'Department of Pathology and Laboratory Medicine, University of Kentucky, Lexington, KY, USA
}

\begin{abstract}
Background-Collagen cross-linking is mediated by lysyl oxidase (LOX) enzyme in the extracellular matrix (ECM) of mitral valve leaflets. Alterations in collagen content and LOX protein expression in the ECM of degenerative mitral valve may enhance leaflet expansion and disease severity.
\end{abstract}

\begin{abstract}
Methods-Twenty posterior degenerative mitral valve leaflets from patients with severe mitral regurgitation were obtained at surgery. Five normal posterior mitral valve leaflets procured during autopsy served as controls. Valvular interstitial cells (VICs) density was quantified by immunohistochemistry, collagen types I and III by picro-sirius red staining and immunohistochemistry, and proteoglycans by alcian blue staining. Protein expression of LOX and its mediator TGF $\beta 1$ were quantified by immunofluorescence and gene expression by PCR.
\end{abstract}

Results-VICs density was increased, structural type I collagen density was reduced, while reparative type III collagen and proteoglycan densities were increased $(\mathrm{p}<0.0001)$ with an increase in spongiosa layer thickness in myxomatous valves. These changes were associated with a reduction in LOX $(\mathrm{p}<0.0001)$ and increase in TGF $\beta 1$ protein expression $(\mathrm{p}<0.0001)$. However, no significant change was seen in gene expression. Linear regression analysis identified a correlation between type I collagen density and LOX grade $\left(\mathrm{R}^{2}=0.855 ; \mathrm{p}<0.0001\right)$.

Conclusions-Reduced type I collagen density with a simultaneous increase in type III collagen and proteoglycan densities possibly contributes to spongiosa layer expansion resulting in incompetent mitral valve leaflets. Observed changes in type I and III collagen densities in DMVD may be secondary to alterations in LOX protein expression, contributing to disorganization of ECM and disease severity.

\footnotetext{
*Address for correspondence: K- Raman Purushothaman MD, FAHA, Assistant Professor of Medicine/Cardiology/Pathology, Icahn School of Medicine at Mount Sinai, Cardiovascular Institute, One Gustave Levy Place, Box 1030, New York, NY 10029, Telephone: 212-241-9782; Fax: 212-241-4080, purushothaman.kothandaraman@mountsinai.org.
} 


\section{Keywords}

Degenerative mitral valve disease; mitral regurgitation; collagen; lysyl oxidase; valvular interstitial cells; extracellular matrix

\section{INTRODUCTION}

Degenerative mitral valve disease (DMVD) complicated by severe mitral regurgitation (MR), is a major cause of cardiovascular morbidity and mortality [1]. Degenerative lesions, such as chordal elongation, chordal rupture and leaflet expansion lead to mitral valve dysfunction that may necessitate surgical repair if severe regurgitation results [2,3]. These lesions are related to altered production of extracellular matrix (ECM), including collagens and proteoglycans $[4,5]$. Valvular interstitial cells (VICs) that include fibroblasts, smooth muscle cells and myofibroblasts are responsible for ECM production [6, 7]. Tissue injury due to mechanical or structural alteration may trigger proliferation and differentiation of fibroblasts into contractile and secretory myofibroblasts that facilitate tissue remodeling [6]. The distinction between normal and pathological degenerative valves depends on the composition and maturation of its ECM components. Collagens play a major role in leaflet stability and during post-translational modification, the collagen protein maturation occurs through cross-linking. Lysyl oxidases (LOX) are a family of matrix remodeling extracellular enzymes that catalyze the cross-linking of collagens and elastin thereby contributing to the maturation of ECM [8]. Such crosslinks result in the formation of thick collagen polymers that provide tensile strength to valve leaflets [4]. LOX is crucial for the maturation of ECM, as evidenced by experimental models which are deficient in LOX and have shown defective ECM [9-12]. We tested the hypothesis that altered collagen composition in DMVD may be associated with a reduction in LOX protein expression. We compared the ECM components including type I and type III collagens, proteoglycan densities and LOX protein expression, in degenerative mitral valve leaflets obtained from patients with severe mitral regurgitation and normal mitral valves identified at autopsy.

\section{METHODS}

\subsection{Sample collection}

Twenty prolapsed posterior mitral valve leaflets were collected from patients who underwent surgical mitral valve repair for severe MR at Mount Sinai Hospital, New York. Five normal posterior mitral valve leaflets, collected from autopsies performed on patients who died of non-cardiac conditions, served as controls. The surgical and autopsy specimens were collected from the P2 segment of the posterior mitral valve leaflet, and immediately fixed in $10 \%$ formalin solution. Following fixation, $2-3 \mathrm{~mm}$ thick sections of the mitral valve leaflet of each case were cut perpendicularly from the annular margin to the free edge margin, and processed into paraffin blocks on the same day. The samples were oriented for paraffin sectioning from the base to the free edge of the leaflet. In addition to specimens fixed in formalin, a small portion of the specimen was freshly frozen, stored at $-80^{\circ} \mathrm{C}$ and later processed for RNA extraction. Pertinent demographic and clinical data were collected from medical records. This study was approved by the Institutional Review Board at Icahn School 
of Medicine at Mount Sinai. Informed consent was obtained from all patients and experiments were conducted per the guidelines of the Declaration of Helsinki principles.

\subsection{Quantification of valvular interstitial cells density}

Deparaffinized valve tissue sections $(5 \mu \mathrm{m})$ were incubated with specific primary antibody using muscle actin monoclonal (C-34931, Enzo, NY) at 1:30 dilution, rabbit polyclonal to vimentin (ab-45939, Abcam, MA) at 1:100 dilution, and rabbit polyclonal to fibroblast specific protein-1 (FSP-1) (ab-27957, Abcam, MA) at 1:100 dilution; and immunohistochemistry was performed using avidin-biotin complex- Elite ABC Vectastain kit (Vector Lab, CA) as described by the manufacturer's instruction. The protein expression was detected by developing with $3^{\prime} 3^{\prime}$-diaminobenzidine chromogen. The cell density was calculated by dividing the number of positive cells by total cell area in $20 \mathrm{X}$ high power field (HPF), as previously published [13]. All images from the histological samples in this study were obtained with an Olympus BX50 microscope and the computerized analysis of the images was performed using the QuantIm (ZEDEC Technologies, Inc) software, except where described. Appropriate control tissues were stained along with test samples by substituting primary antibody for IgG or specific IgG isotypes from the same species and at the same final concentration as the primary antibody [14]. Quantification included all the three valve layers: atrialis, spongiosa and ventricularis. All measurements were done from the base to the free edge of the leaflet section.

\subsection{Quantification of collagen and proteoglycan density}

Deparaffinized valve tissue sections $(5 \mu \mathrm{m})$ were used to measure type I and III collagen densities using picro-sirius red stain and evaluated with polarized microscopy as previously published [15]. Furthermore, specific immunohistochemistry was performed using anticollagen I antibody (ab90395, Abcam, MA), at 1:100 dilution; and anti-collagen III antibody (ab7778, Abcam, MA), at 1:200 dilution. Appropriate positive and negative controls for type I and III collagen were included using human uterine tissue. Collagen density was measured with computerized planimetry [15] and graded the area stained by collagen as follows: grade 0: no stain; grade 1: upto $25 \%$ positive; grade 2 : $>26-50 \%$ positive; and grade $3:>50 \%$ positive stained area. To measure proteoglycans, valve tissue sections were stained with $1 \%$ alcian blue at pH2.5 per manufacturer's instruction (Polyscientific, NY), imaged with 20X objective, and the proteoglycan density was evaluated using computerized digital planimetry by measuring the proteoglycan stained area, divided by the total valve area measured.

\subsection{Quantification of thickness of histological layers of mitral valve leaflet}

Using hematoxylin and eosin (H\&E) stained sections, the thickness and composition of each of the histological layers of mitral valve leaflets were analyzed separately and compared among each other. The following parameters were measured: 1) atrialis layer thickness, 2) spongiosa layer thickness, and 3) ventricularis layer thickness. The expansion of spongiosa layer and infiltration into ventricularis was semi quantitatively scored (Grade 0-3). Grade 0: no expansion of spongiosa layer; grade 1: mild expansion ( $\iota 5 \%$ ); grade 2: moderate expansion (25-75\%); and grade 3: showing severe expansion ( $\geq 75 \%$ ) with infiltration into ventricularis layer. 


\subsection{Quantification of LOX and TGF $\beta$ protein expression}

Deparaffinized tissue sections $(5 \mu \mathrm{m})$ were incubated with specific primary rabbit polyclonal anti-LOX propeptide (Novus biologicals, CA), at 1:100 dilution. Immunohistochemistry was performed and evaluated as described previously (section 2.2). Appropriate positive and negative controls using human liver tissue were included to distinguish non-specific binding. The level of LOX protein expression was graded as per the area stained by LOX as follows: grade 0: no stain; grade 1: upto $25 \%$ positive; grade 2: $>26-50 \%$ positive; grade $3:>50 \%$ positive stained area. Furthermore, LOX expression was also confirmed by immunofluorescence using the same primary antibody with a secondary donkey anti-rabbit Alexa Fluor 594 (A-21207, Invitrogen, CA) at 1:250 dilution. Images were acquired using Leica TCS SP5 DMI confocal microscope and analyzed using ImageJ software (NIH). Using specific mouse monoclonal antibody for TGF $\beta 1$ (Abcam, MA) the density of TGF $\beta 1$ was quantified using immunofluorescence as described above for LOX quantification.

\subsection{Quantification of gene expression of collagens, LOX and TGF $\beta 1$}

Total RNA was isolated from mitral valve leaflets, as previously reported [16]. The RNA concentration was quantified using Nanodrop and reverse transcribed to cDNA using TaqMan reverse transcription reagents (Applied Biosystems, CA). The cDNA was used to measure the mRNA expression by quantitative real-time PCR with specific primer sequence for collagen I (Col1A1), frd: $5^{\prime}$-gattccetggacctaaaggtgc- $3^{\prime}$ and rev: $5^{\prime}$ agcctctccatctttgccagca- $3^{\prime}$; collagen-III (COL3A1), frd: $5^{\prime}$-tggtctgcaaggaatgcctgga- $3^{\prime}$ and rev: $5^{\prime}$-tctttccctgggacaccatcag- $3^{\prime}$; LOX, frd: $5^{\prime}$-gatacggcactggctacttcca- $3^{\prime}$ and rev: $5^{\prime}$ gccagacagttttcctccgcc- $3^{\prime}$; and TGF $\beta 1$, frd: $5^{\prime}$-gcagcacgtggagctgta- $3^{\prime}$; and rev: $5^{\prime}$ cagccggttgctgaggta- $3^{\prime}$. The mRNA expression was normalized to the house keeping gene beta actin.

\subsection{Statistical analysis}

Data are presented as mean \pm SEM. For 2-group comparisons, Gaussian distribution samples were compared by 2-tailed Student $t$ test, preceded by Levene $\mathrm{F}$ test for equality of variances. Non-Gaussian-distribution samples were compared by Mann-Whitney nonparametric test. For multiple comparisons, one-way ANOVA was used. The following variables were included in the analysis: sex, diabetes mellitus, hypertension, coronary artery disease, smoking, (dichotomous variables); severity of myxoid area infiltration grade, (ordinal variables with values of $0,1,2,3$ ); age, blood glucose levels, body mass index, atrialis layer thickness, spongiosa layer thickness, ventricularis layer thickness, type I and III collagen density, proteoglycan density, FSP-1, vimentin and a-actin densities, gene expression of type I and III collagens, LOX, and TGF $\beta 1$ (continuous variables). IBM SPSS/ PASW Statistics 20 (SPSS Inc. Chicago, Illinois) software was used for the analysis. p-value $<0.05$ was considered significant. 


\section{RESULTS}

\subsection{Demographic and clinical profile}

Demographic and clinical profiles were similar between DMVD and control (normal) group

(Table 1). There was no statistically significant difference in age, sex, prevalence of diabetes mellitus, hypertension, coronary artery disease and smoking between the groups ( $>0.2)$. There were no reports of rheumatic or infective endocarditis etiology among the studied cases. All subjects with DMVD corresponded to degenerative, non-syndromic, non-ischemic etiologies. All subjects in DMVD group had severe mitral regurgitation according to echocardiography evaluation; six of them (30\%) presented with chordae rupture, and their distribution according to New York Heart Association (NYHA) Functional Classification was: class II $=7(35 \%)$, class III $=12(60 \%)$, class IV $=1(5 \%)$; left ventricular ejection fraction (LVEF) was $>59 \%$ in 12 patients (60\%) and 40-59\% in 8 patients (40\%).

\subsection{Valvular interstitial cells density}

VICs (fibroblast, myofibroblast and smooth muscle cell) density was significantly increased in degenerative mitral valve leaflets compared to control leaflets; FSP-1 (163 \pm 5 vs 41 $\pm 6.5 ; \mathrm{p}<0.0001)$, vimentin $(114 \pm 4$ vs $46.7 \pm 2 ; \mathrm{p}<0.0001)$ and $\mathrm{a}$-actin $(90.5 \pm 3.4$ vs 46 $\pm 4 ; \mathrm{p}<0.0001$ ) (Figure 1).

\subsection{ECM composition: type I and III collagen and proteoglycan density}

The picro-sirius red staining analysis showed a significant decrease in structural type I collagen density in degenerative mitral valve leaflets compared to control $(0.17 \pm 0.01$ vs. $0.66 \pm 0.01 ; p<0.0001)$, whereas, reparative type III collagen density was significantly increased in degenerative mitral valve leaflets $(0.49 \pm 0.02$ vs. $0.18 \pm 0.01 ; \mathrm{p}<0.0001)$ (Figure 2A-D). Immunohistochemistry evaluation of type I and type III collagen showed a similar result with a significant decrease in type I collagen ( $0.85 \pm 0.17$ vs. $2.8 \pm 0.07 ; \mathrm{p}=$ $0.0001)$ and an increase in type III collagen $(2.7 \pm 0.06$ vs. $0.9 \pm 0.06 ; p=0.0001)$ in degenerative mitral valve leaflets compared to control (Figure 2E-J). Proteoglycan density was also significantly increased in degenerative mitral valve leaflets compared to control $(0.5 \pm 0.03$ vs. $0.16 \pm 0.02 ; \mathrm{p}<0.0001)$ (Figure $3 \mathrm{~A}-\mathrm{C})$.

\subsection{Histological layer thickness and spongiosa layer expansion}

The spongiosa layer thickness was significantly increased in degenerative mitral valve leaflets compared to control (983 $\pm 87 \mu \mathrm{m}$ vs. $63 \pm 8.9 \mu \mathrm{m}$; p<0.0001) (Figure 3D-F). The atrialis layer thickness was moderately increased, whereas, there was no significant change in the ventricularis layer thickness (Table 2). The myxoid region of the spongiosa layer expansion was seen to extend and infiltrate into the ventricularis layer only in degenerative mitral valve leaflets, whereas, there was no infiltration in control mitral valve leaflets. The infiltration into the ventricularis layer paralleled with the histological severity of DMVD. This was demonstrated by correlating increased spongiosa layer thickness to histological grade severity of infiltration of spongiosa layer into ventricularis layer (Figure 4). 


\subsection{LOX and TGF- $\beta 1$ protein and gene expression}

LOX expression was significantly decreased in degenerative mitral valve leaflets compared to control $(0.46 \pm 0.07$ vs $2.4 \pm 0.22 ; \mathrm{p}<0.0001)$ (Figure $5 \mathrm{~A}-\mathrm{C})$. Immunofluorescent images further confirmed that LOX expression was reduced in degenerative mitral valve leaflets, despite an increase in cellular content (DAPI staining) (Figure 5D-E). In addition, linear regression analysis identified a correlation between type I collagen density and LOX grade $\left(r^{2}=0.855 ; p<0.0001\right)$ (Figure $\left.5 F\right)$. The TGF $\beta 1$ protein expression was significantly increased in degenerative mitral valve leaflets compared to control mitral valve leaflets (4.5 \pm 0.39 vs $1.08 \pm 0.04 ; \mathrm{p}<0.0001$ ) (Figure $5 \mathrm{G}-\mathrm{I}$ ). There was no significant change in gene expression of type I collagen ( $1.9 \pm 0.18$ vs $3.22 \pm 0.49 ; \mathrm{p}=\mathrm{NS})$, type III collagen $(1.78 \pm 0.2$ vs $1.6 \pm 0.56 ; \mathrm{p}=\mathrm{NS})$, LOX $(4.25 \pm 0.26$ vs $3.3 \pm 0.45 ; \mathrm{p}=\mathrm{NS})$ and TGF $\beta 1(5.75 \pm 0.08$ vs $5.56 \pm 0.45 ; \mathrm{p}=\mathrm{NS}$ ) in degenerative mitral valve leaflets compared to control.

\section{DISCUSSION}

DMVD is considered to be a potential cause of mitral valve prolapse resulting in mitral regurgitation (MR) [17]. Advanced DMVD with rupture of chordae tendineae leads to severe MR and clinically presents with cardiac decompensation [18, 19]. Valvular leaflet expansion caused by enhanced VICs and production of altered extracellular matrix (ECM) in the spongiosa layer seems to facilitate the lesion progression in DMVD [20]. Structural alterations in the cellular and ECM are possibly due to associated modifications of regulatory enzymes and growth factors. We have here investigated a pathological association of cellular density and altered ECM proteins in advanced DMVD, which could have implications in disease progression.

In the present study, we observed in degenerative mitral valve leaflets an increased density of VICs associated with excessive production of ECM, including altered collagen and increased proteoglycan deposition (Figure 6). This is in accordance to previous studies, which have documented proliferation of VICs leading to increased ECM in DMVD [21, 22]. When quantifying distinct collagen types, the structural type I collagen was significantly decreased, whereas, immature type III collagen was significantly increased. To explore the mechanisms involved in the reduction of type I collagen, we quantified the cross-linking enzyme LOX. The protein expression of LOX was reduced, pointing to a correlation to the observed decrease in type I collagen density. Simultaneously, we observed an increase in type III collagen and proteoglycan content resulting in increased spongiosa layer thickness. This suggests a reparative or compensatory mechanism that resulted in disorganized ECM composition. Excessive production of proteoglycan interferes with the normal assembly of collagen fibrils and remodeling [23] and may be responsible for improper assembly of collagen fibers resulting in severe mitral regurgitation.

During collagen synthesis, collagen molecules undergo several post-translational modifications that facilitate their cross-linking and consequently the formation of collagen fibers. A key enzyme in this process is LOX, which initiates lysine and hydroxylysinederived cross-linking of fibrillar collagen molecules such as type I collagen [11, 24, 25]. The significant decrease in type I collagen density observed in this study indicates impairment in the formation of thick functional type I collagen fibers. Whereas, type III collagen is more 
extensible, weaker and immature than thick structural type I collagen; and the synthesis of type III collagen occur in response to injury [26], independent of LOX. Collagen tensile strength mainly relies on the cross-linking; and, it is considered that not only the content of collagen, but its cross-linking which has an impact on stiffness [27]. LOX gene expression was not altered in this study; however, the decrease in LOX protein expression is suggestive of alterations in post-translational modification. LOX is synthesized as a pre-protein and after signal peptide hydrolysis, glycosylation, copper incorporation, and lysine tyrosylquinone generation, the enzyme is released into ECM, where it is processed to form mature LOX [28]. Any defect in post-translational modification results in defective LOX expression and activity. These data suggest that LOX plays a key role in the formation of cross-linked type I collagen fibers. Furthermore, no significant change in the gene expression of type I and type III collagen was observed in this study and no mutations in genes coding for collagen have been reported in DMVD [29].

Finally, TGF $\beta$ is known to interact with ECM components and has been shown to be implicated in both familial and syndromic mitral valve prolapse [30]. LOX, being a key regulator of ECM maturation modulates TGF $\beta$ activation. It has been reported that absence or reduced LOX activity augments TGF $\beta$ signaling, demonstrating that LOX attenuates TGF $\beta$ signaling [31]. Also, it has been described that when LOX expression/activity is reduced, the subsequent inefficient cross-linking of collagens, results in reduction of their tensile strength and interestingly also increases their solubility, and thereof higher propensity to proteolysis, possibly responsible for augmentation of TGF $\beta$ in the tissue [32]. Although more experimentation is required on both signaling pathways, based on our findings, we report low levels of LOX in association with reduction in type I collagen density in DMVD results in leaflet instability and severe mitral valve disease.

This is an observational study correlating an association of LOX with ECM changes, without establishing an actual causation for mitral valve degeneration, which is a limitation of this study. Also, blood samples were not available to investigate enzyme activity; and acquisition of samples to serve as control was restricted by the number of specimens from autopsy. However, our study documents crucial alterations in type I collagen density and LOX expression with ECM disorganization in DMVD.

\section{CONCLUSION}

In this study, we have documented an increase in VICs density associated with excessive production of ECM components. Reduction in thick type I collagen density associated with compensatory increase in type III collagen and proteoglycan deposition may be related to impaired cross-linking of type I collagen mediated by LOX. These changes also contribute to a derangement of the ECM composition, leading to increased spongiosa layer thickness, a histological marker of mitral valve disease severity.

\section{Acknowledgments}

FUNDING 
The authors acknowledge funding from the Zena and Michael A. Weiner Cardiovascular Institute, Department of Cardiovascular Surgery, Icahn School of Medicine at Mount Sinai, New York and from National Institutes of Health (NIH)/NHLBI through grant K01HL133424 (to ICT).

The authors acknowledge the professional consultation of Dr. Baber Usman MD, Director of Biometrics, Cardiovascular Institute, for the statistical review of this manuscript. Confocal microscopy was performed at the Microscopy CoRE at Icahn School of Medicine at Mount Sinai.

\section{References}

1. Avierinos JF, Gersh BJ, Melton LJ 3rd, Bailey KR, Shub C, Nishimura RA, et al. Natural history of asymptomatic mitral valve prolapse in the community. Circulation. 2002; 106:1355-61. [PubMed: 12221052]

2. Anyanwu AC, Adams DH. Etiologic classification of degenerative mitral valve disease: Barlow's disease and fibroelastic deficiency. Semin Thorac Cardiovasc Surg. 2007; 19:90-6. [PubMed: 17870001]

3. Carpentier, A., Adams, DH., Filsoufi, F. Text book of Carpentier's Reconstructive Valve Surgery. Maryland Heights, MS: Saunders Elsevier; 2010. p. 345

4. Whittaker P, Boughner DR, Perkins DG, Canham PB. Quantitative structural analysis of collagen in chordae tendineae and its relation to floppy mitral valves and proteoglycan infiltration. Br Heart J. 1987; 57:264-9. [PubMed: 3566985]

5. Grande-Allen KJ, Griffin BP, Ratliff NB, Cosgrove DM, Vesely I. Glycosaminoglycan profiles of myxomatous mitral leaflets and chordae parallel the severity of mechanical alterations. J Am Coll Cardiol. 2003; 42:271-7. [PubMed: 12875763]

6. Schoen FJ. Mechanisms of function and disease of natural and replacement heart valves. Ann rev pathol. 2012; 7:161-83. [PubMed: 21942526]

7. Rabkin E, Aikawa M, Stone JR, Fukumoto Y, Libby P, Schoen FJ. Activated interstitial myofibroblasts express catabolic enzymes and mediate matrix remodeling in myxomatous heart valves. Circulation. 2001; 104:2525-32. [PubMed: 11714645]

8. Busnadiego O, Gorbenko Del Blanco D, Gonzalez-Santamaria J, Habashi JP, Calderon JF, Sandoval $\mathrm{P}$, et al. Elevated expression levels of lysyl oxidases protect against aortic aneurysm progression in Marfan syndrome. J Mol Cell Cardiol. 2015; 85:48-57. [PubMed: 25988230]

9. Kanematsu Y, Kanematsu M, Kurihara C, Tsou TL, Nuki Y, Liang EI, et al. Pharmacologically induced thoracic and abdominal aortic aneurysms in mice. Hypertension. 2010; 55:1267-74. [PubMed: 20212272]

10. Liu X, Zhao Y, Gao J, Pawlyk B, Starcher B, Spencer JA, et al. Elastic fiber homeostasis requires lysyl oxidase-like 1 protein. Nat Genet. 2004; 36:178-82. [PubMed: 14745449]

11. Maki JM. Lysyl oxidases in mammalian development and certain pathological conditions. Histol Histopathol. 2009; 24:651-60. [PubMed: 19283672]

12. Remus EW, O’Donnell RE Jr, Rafferty K, Weiss D, Joseph G, Csiszar K, et al. The role of lysyl oxidase family members in the stabilization of abdominal aortic aneurysms. Am J Physiol Heart Circ Physiol. 2012; 303:H1067-75. [PubMed: 22904155]

13. Purushothaman KR, Purushothaman M, Levy AP, Lento PA, Evrard S, Kovacic JC, et al. Increased expression of oxidation-specific epitopes and apoptosis are associated with haptoglobin genotype: possible implications for plaque progression in human atherosclerosis. J Am Coll Cardiol. 2012; 60:112-9. [PubMed: 22766337]

14. Purushothaman KR, Krishnan P, Purushothaman M, Wiley J, Alviar CL, Ruiz FJ, et al. Expression of angiotensin-converting enzyme 2 and its end product angiotensin 1-7 is increased in diabetic atheroma: implications for inflammation and neovascularization. Cardiovasc Pathol. 2013; 22:428. [PubMed: 22749485]

15. Purushothaman KR, Meerarani P, Muntner P, Lento PA, O’Connor WN, Sharma SK, et al. Inflammation, neovascularization and intra-plaque hemorrhage are associated with increased reparative collagen content: Implication for plaque progression in diabetic atherosclerosis. Vasc Med. 2011; 16:103-8. [PubMed: 21511672] 
16. Purushothaman M, Krishnan P, Purushothaman KR, Baber U, Tarricone A, Perez JS, et al. Genotype-dependent impairment of hemoglobin clearance increases oxidative and inflammatory response in human diabetic atherosclerosis. Arterioscler Thromb Vasc Biol. 2012; 32:2769-75. [PubMed: 22982461]

17. Adams DH, Rosenhek R, Falk V. Degenerative mitral valve regurgitation: best practice revolution. Eur Heart J. 2010; 31:1958-66. [PubMed: 20624767]

18. Gabbay U, Yosefy C. The underlying causes of chordae tendinae rupture: a systematic review. Int J Cardiol. 2010; 143:113-8. [PubMed: 20207434]

19. Takamoto T, Nitta M, Tsujibayashi T, Taniguchi K, Marumo F. The prevalence and clinical features of pathologically abnormal mitral valve leaflets (myxomatous mitral valve) in the mitral valve prolapse syndrome: an echocardiographic and pathological comparative study. J Cardiol Suppl. 1991; 25:75-86. [PubMed: 1888468]

20. Prunotto M, Caimmi PP, Bongiovanni M. Cellular pathology of mitral valve prolapse. Cardiovasc Pathol. 2009; 19:e113-7. [PubMed: 19375355]

21. Rabkin-Aikawa E, Farber M, Aikawa M, Schoen FJ. Dynamic and reversible changes of interstitial cell phenotype during remodeling of cardiac valves. J Heart Valve Dis. 2004; 13:841-7. [PubMed: 15473488]

22. Gupta V, Barzilla JE, Mendez JS, Stephens EH, Lee EL, Collard CD, et al. Abundance and location of proteoglycans and hyaluronan within normal and myxomatous mitral valves. Cardiovasc Pathol. 2009; 18:191-7. [PubMed: 18621549]

23. Halper J. Proteoglycans and diseases of soft tissues. Adv Exp Med Biol. 2014; 802:49-58. [PubMed: 24443020]

24. Csiszar K. Lysyl oxidases: a novel multifunctional amine oxidase family. Prog Nucleic Acid Res Mol Biol. 2001; 70:1-32. [PubMed: 11642359]

25. Myllyharju J, Kivirikko KI. Collagens, modifying enzymes and their mutations in humans, flies and worms. Trends Genet. 2004; 20:33-43. [PubMed: 14698617]

26. Doillon CJ, Dunn MG, Bender E, Silver FH. Collagen fiber formation in repair tissue: development of strength and toughness. Coll Relat Res. 1985; 5:481-92. [PubMed: 3833451]

27. Gonzalez-Santamaria J, Villalba M, Busnadiego O, Lopez-Olaneta MM, Sandoval P, Snabel J, et al. Matrix cross-linking lysyl oxidases are induced in response to myocardial infarction and promote cardiac dysfunction. Cardiovasc Res. 2016; 109:67-78. [PubMed: 26260798]

28. Rodriguez C, Martinez-Gonzalez J, Raposo B, Alcudia JF, Guadall A, Badimon L. Regulation of lysyl oxidase in vascular cells: lysyl oxidase as a new player in cardiovascular diseases. Cardiovasc Res. 2008; 79:7-13. [PubMed: 18469024]

29. Henney A, Tsipouras P, Schwartz RC, Child AH, Devereux RB, Leech GJ. Genetic evidence that mutations in the COL1A1, COL1A2, COL3A1, or COL5A2 collagen genes are not responsible for mitral valve prolapse. Br Heart J. 1989; 61:292-9. [PubMed: 2930668]

30. Ng CM, Cheng A, Myers LA, Martinez-Murillo F, Jie C, Bedja D, et al. TGF-beta-dependent pathogenesis of mitral valve prolapse in a mouse model of Marfan syndrome. J Clin Invest. 2004; 114:1586-92. [PubMed: 15546004]

31. Atsawasuwan P, Mochida Y, Katafuchi M, Kaku M, Fong KS, Csiszar K, et al. Lysyl oxidase binds transforming growth factor-beta and regulates its signaling via amine oxidase activity. J Biol Chem. 2008; 283:34229-40. [PubMed: 18835815]

32. Kutchuk L, Laitala A, Soueid-Bomgarten S, Shentzer P, Rosendahl AH, Eilot S, et al. Muscle composition is regulated by a Lox-TGFbeta feedback loop. Development. 2015; 142:983-93. [PubMed: 25715398] 


\section{Highlights}

- Lysyl oxidase enzyme mediates collagen cross-linking in the extracellular matrix.

- $\quad$ Reduced Lysyl oxidase may alter type I and type III collagens in spongiosa layer.

- $\quad$ Spongiosa layer expansion may enhance leaflet instability and disease severity. 


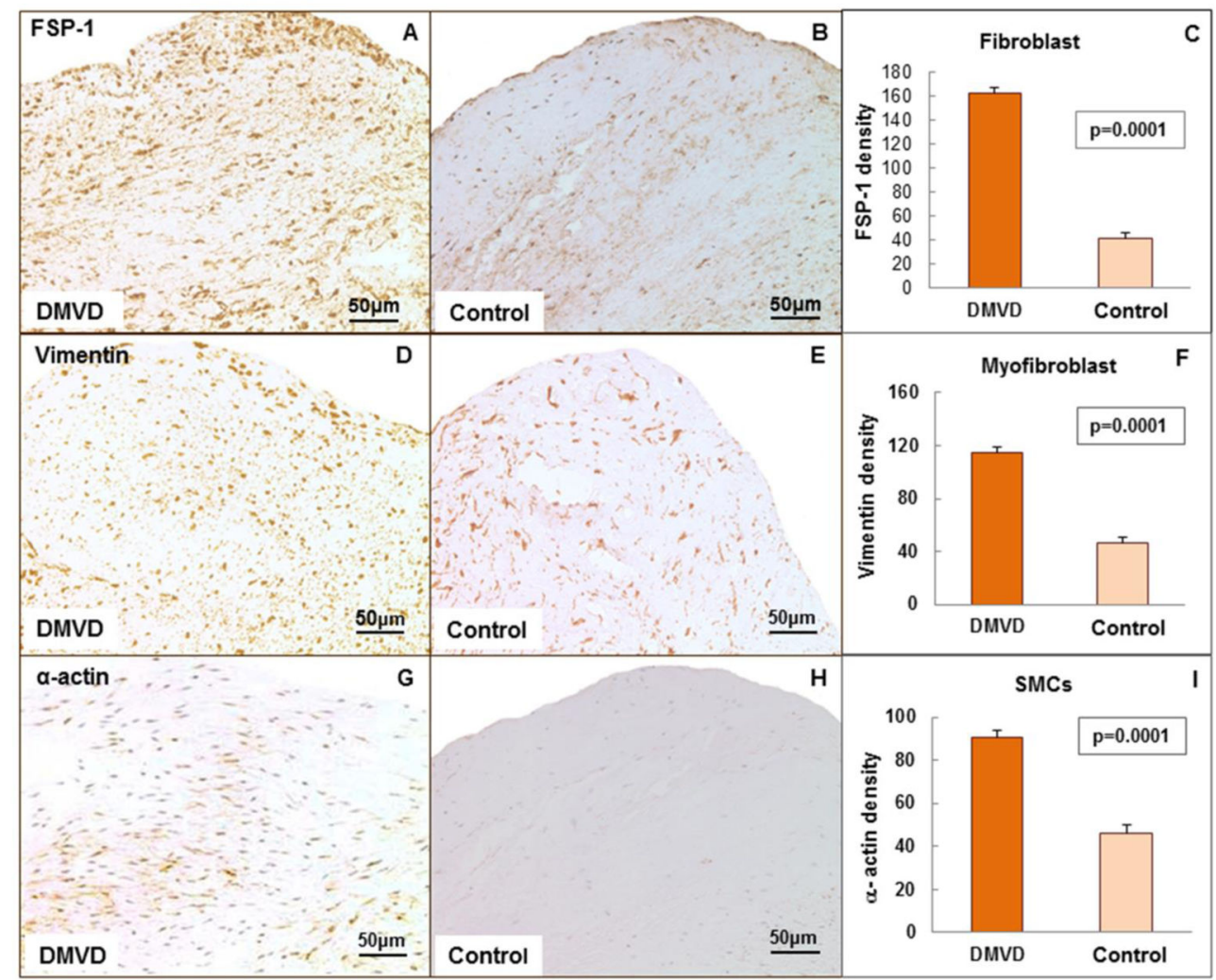

Figure 1.

Valvular interstitial cell density in posterior degenerative mitral valve leaflets compared to control. Representative images from immunohistochemical staining with primary antibodies chosen to detect $(\mathbf{A}, \mathbf{B})$ fibroblast (FSP-1), (D,E) myofibroblasts (vimentin), and $(\mathbf{G}, \mathbf{H})$ smooth muscle cells (a-actin); scale bar $=50 \mu \mathrm{m}$. Corresponding bar graphs show quantification of positive cells per high power field for FSP-1 (C), vimentin (F) and a-actin (I). 

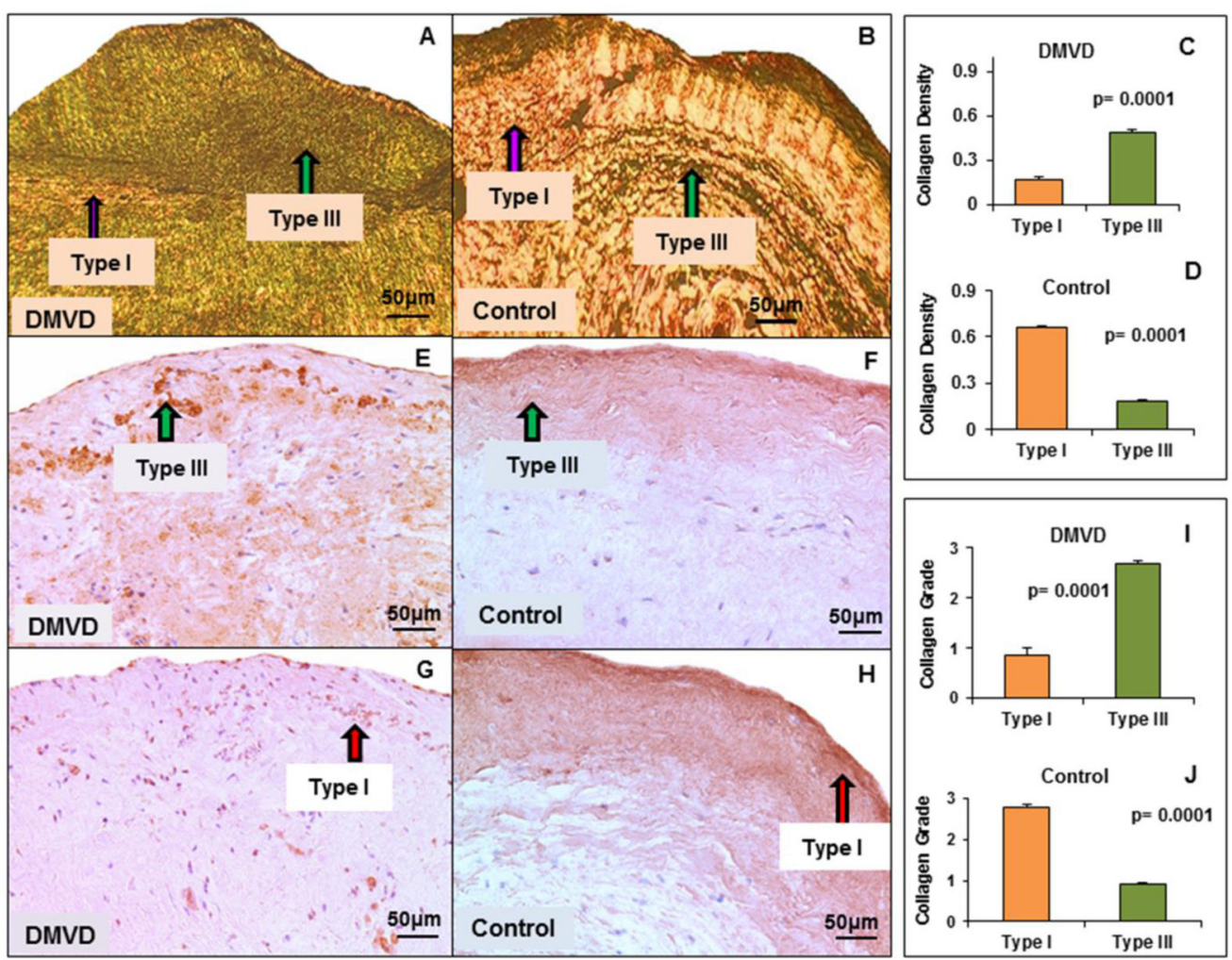

Figure 2.

Type I and III collagen density in degenerative mitral valve leaflets compared to control. Representative images of picro-sirius red stained sections from DMVD (A) and control (B) posterior mitral valve leaflets and corresponding quantification of collagen density measured with polarized microscopy (C,D). Representative immunohistochemistry images for type III $(\mathbf{E}, \mathbf{F})$ and type I $(\mathbf{G}, \mathbf{H})$ collagens; and corresponding measurement of collagen abundance by grade $(\mathbf{I}, \mathbf{J})$. Scale bar $=50 \mu \mathrm{m}$. 


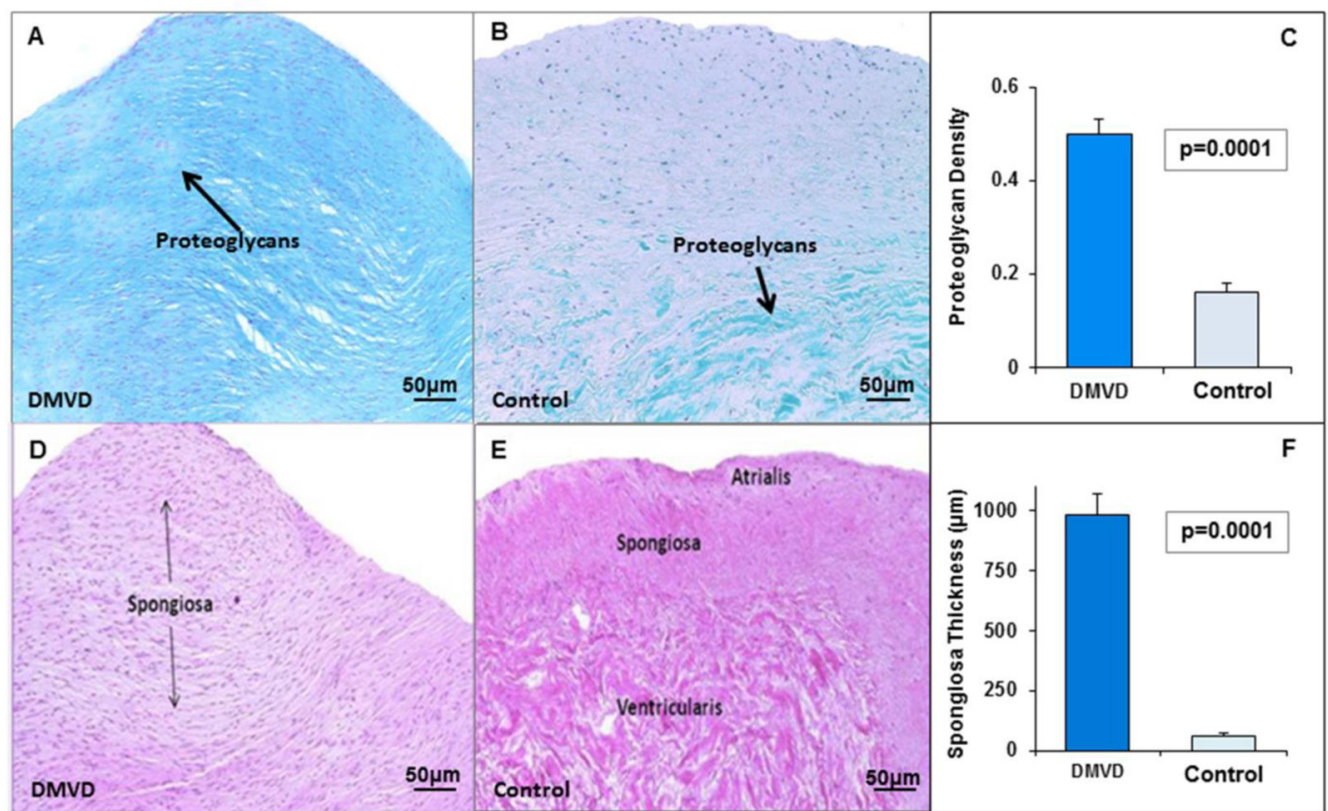

Figure 3.

Proteoglycan expression in degenerative mitral valves leaflets compared to control. $(\mathbf{A}, \mathbf{B})$ Representative image of sections stained with $1 \%$ alcian blue; and corresponding quantification of proteoglycan density (C). Hematoxylin and eosin (H\&E) stained sections showing the spongiosa layer in degenerative mitral (D) compared to control (E), and the corresponding quantification of the spongiosa layer thickness $(\mathbf{F})$. Scale bar $=50 \mu \mathrm{m}$. 

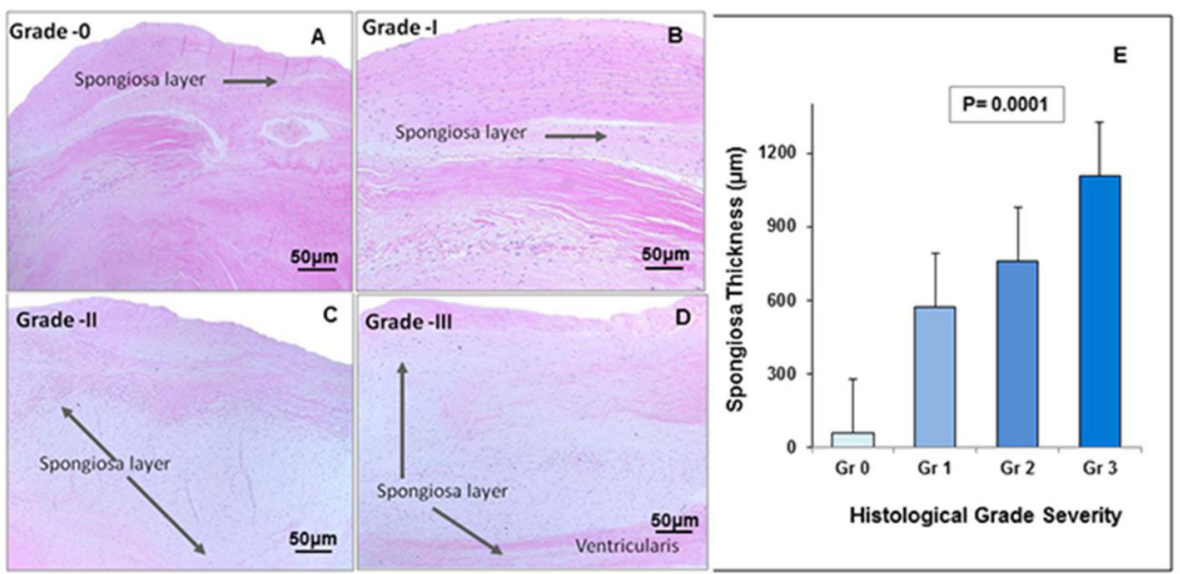

Figure 4.

Histological grading of spongiosa layer expansion in degenerative mitral valve leaflets. (AD) Representative $H \& E$ stained sections of degenerative mitral valve leaflets depicting the different grades of spongiosa layer expansion, with grade 3 (D) involving extension into the ventricularis layer. Scale bar $=50 \mu \mathrm{m}$. $(\mathbf{E})$ Bar graph shows the correlation of spongiosa layer expansion in thickness $(\mu \mathrm{m})$ to histological grade severity. 

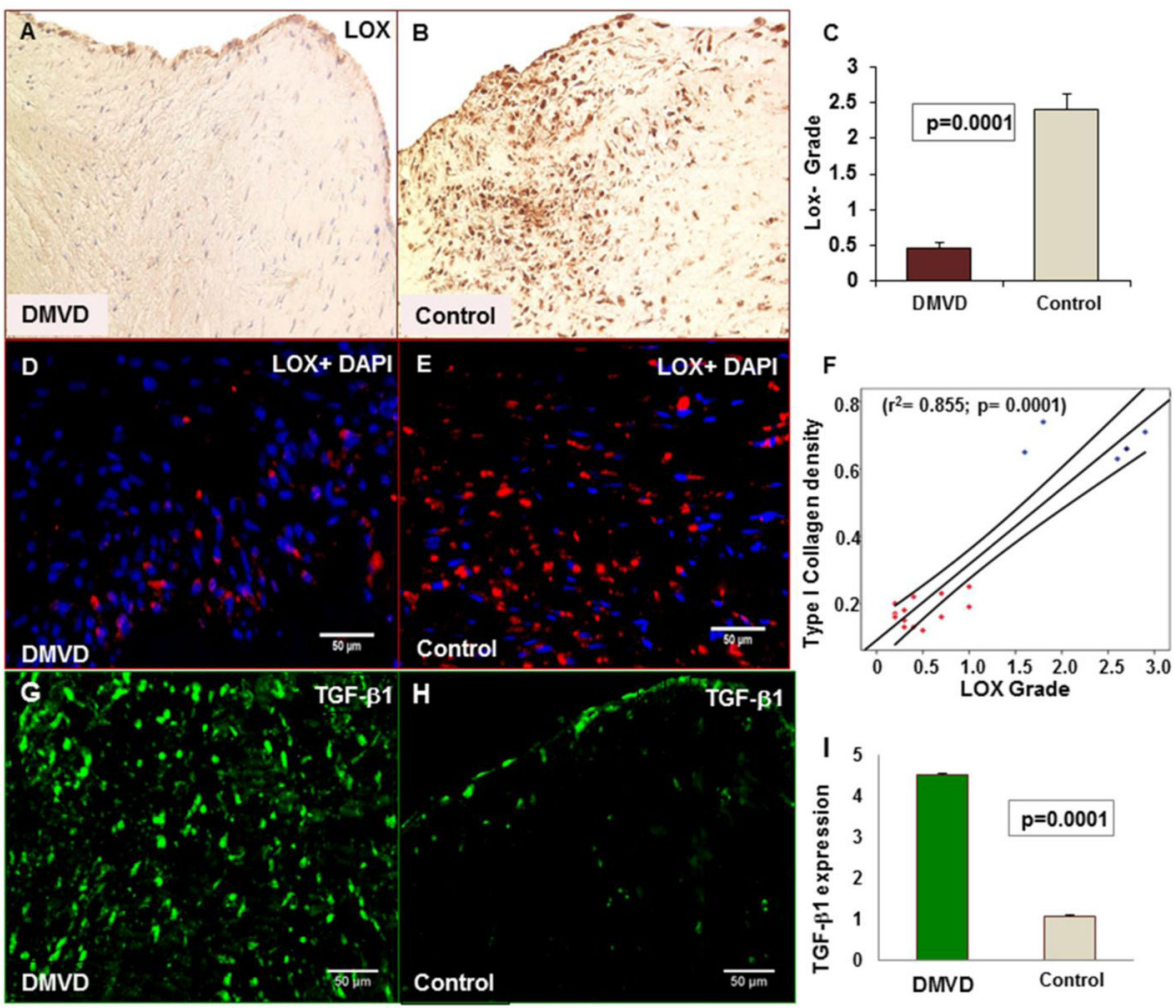

Figure 5.

LOX and TGF $\beta 1$ expression in degenerative mitral valve leaflets compared to control. (A, B) LOX expression in degenerative and control valve leaflets by immunohistochemistry and (D, E) by immunofluorescence. (C) Bar graph shows quantification of LOX expression by grade from immunohistochemistry images. (F) Linear regression analysis shows a positive correlation between mean LOX grade and type I collagen density. (G, H) TGF- $\beta 1$ expression in degenerative and control valve leaflets by immunofluorescence; (I) bar graph shows corresponding quantification of TGF- $\beta 1$ expression. Scale bar $=50 \mu \mathrm{m}$. 


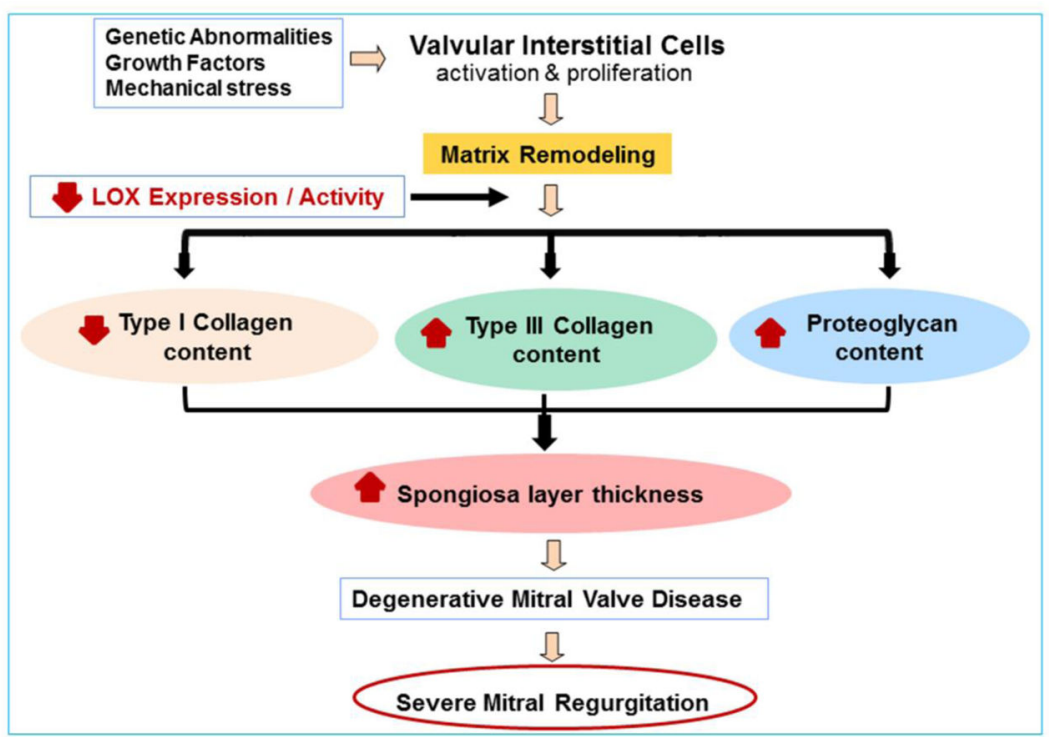

Figure 6.

Schematic of proposed model of the role of LOX protein in DMVD. The mechanical integrity of valve leaflets is dependent on a properly structured extracellular matrix (ECM), which is produced by the valvular interstitial cells (VICs). VICs activation and proliferation are mediated by genetic abnormalities, growth factors, and mechanical forces. In this study, we observed a reduction in type I collagen density, while type III collagen and proteoglycan densities were increased resulting in spongiosa layer expansion. In addition, we observed a reduction in LOX protein expression, the crucial enzyme involved in collagen cross-linking. We speculate that in DMVD, a defective cross-linking of type I collagen by reduced LOX protein expression may be associated with disorganization of ECM resulting in disease severity. 


\section{Table 1}

Demographic and clinical data

\begin{tabular}{lccc}
\hline & Degenerative mitral valve $(\mathbf{n = 2 0})$ & Normal valve (control) $(\mathbf{n = 5})$ & p-value \\
\hline Age (Years) & $51.05 \pm 3.6$ & $51.08 \pm 14.8$ & 0.94 \\
Sex (\%) Female & 30 & 40 & 0.7 \\
Coronary Artery Disease (\%) & 60 & 40 & 0.5 \\
Diabetes Mellitus (\%) & 60 & 40 & 0.5 \\
Hypertension (\%) & 50 & 40 & 0.7 \\
Smoking (\%) & 60 & 40 & 0.5 \\
Blood Glucose (mg/dl) & $123.7 \pm 6.1$ & $122.0 \pm 9.0$ & 0.88 \\
Body Mass Index $\left(\mathrm{kg} / \mathrm{m}^{2}\right)$ & $26.1 \pm 1.0$ & $23.9 \pm 0.4$ & 0.27 \\
\hline
\end{tabular}

Data are expressed as mean \pm SEM, or percentage. Statistical differences between degenerative mitral valve and normal valve (control) groups are shown. 


\section{Table 2}

\section{Histological Parameters}

\begin{tabular}{lccc}
\hline & Degenerative mitral valve $(\mathbf{n}=\mathbf{2 0})$ & Normal valve $($ control $)(\mathbf{n}=\mathbf{5})$ & p-value \\
\hline Atrialis Layer Thickness $(\mu \mathrm{m})$ & $324 \pm 11.7$ & $93 \pm 16.6$ & 0.0001 \\
Spongiosa Layer Thickness $(\mu \mathrm{m})$ & $938 \pm 87.1$ & $63 \pm 8.9$ & 0.0001 \\
Ventricularis Layer Thickness $(\mu \mathrm{m})$ & $527 \pm 26.2$ & $472 \pm 25.2$ & $\mathrm{NS}$ \\
Myxoid area extension into Ventricularis $(\mu \mathrm{m})$ & $0.85 \pm 0.1$ & 0.00 & 0.0001 \\
Grade - severity $(0-3)$ & $2.6 \pm 0.2$ & 0.00 & 0.0001 \\
\hline
\end{tabular}

Data are expressed as mean \pm SEM. Statistically significant differences between degenerative mitral valve and normal valve (control) groups are shown. 